\title{
DETERMINATION OF GOLD IN GOLD JEWELLERY ALLOYS BY ICP SPECTROMETRY*
}

\author{
M. Brill \\ \& \\ K.-H. Wiedemann \\ W. C. Heraeus GmbH, \\ Hanau, Germany
}

As a result of recent research and development work supported by World Gold Council, Inductively Coupled Plasma Spectrometry (ICP) is rapidly emerging as a serious and viable alternative to the centuries-old cupellation or fire assay method for the determination of gold in gold jewellery alloys.

\section{INTRODUCTION}

No sector of industry makes such great demands on the performance of the methods for the analysis of elements as that of precious metal chemistry. Since only at a relatively few places in the world is the whole range of precious metals activities to be found - from primary winning, manufacture of typical products, through to recycling - only a few specialists have experience with all the analytical methods available today for the analysis of precious metals.

Consequently, the impact of new spectrometric techniques has been felt only during the last few years. But today, in addition to the widespread use of large spectrometers for quality control, spectrometry is now beginning to play an important role in the fineness analysis of gold alloys and other precious metals used in the jewellery sector.

\section{Cupellation or Fire Assay}

The determination of the gold content in gold jewellery alloys has hitherto been carried out with unrivalled precision by the 'cupellation' or fire assay method [1]. The basis of this method is that the gold jewellery alloy specimen for analysis is diluted with silver and, together with added lead, is melted in a cupellation

\footnotetext{
* This paper is based on an earlier version originally published in German in Metall, 1991, 45(7), 656-62.
} 
crucible (magnesium oxide) so that the lead is progressively converted into lead oxide. In this process, the lead oxide takes up the oxides of the base metal part in the form of a molten glass that drains away from the hot metal bead and diffuses into the porous crucible. The metal button remaining after this cupellation process essentially consists of gold and the excess of added silver. The silver is extracted from the flattened noble metal button in nitric acid leaving the gold. The gold content of the sample is then accurately determined by weighing.

From time immemorial, the cupellation technique outlined above has been the most precise method available for the determination of gold content subject to the proviso that the material to be investigated satisfies the ideal conditions for the application of the technique, as is the case for gold-silver-copper alloys.

However, the rapid development of new materials with the use, for example, of platinum metals in goldcontaining alloys, is continuously presenting the analyst with new problems for the adaptation of their traditional methods. In the most extreme cases this has led to the abandoning of these methods.

It is not surprising that in view of technical progress and the opening up of the international markets, various efforts have been made to ensure international harmonization of the analytical methods used for the testing and designation of goods made of precious metals. The ISO (International Organization for Standardization) Technical Committee TC 174: Jewellery, and the corresponding CEN (Comité Européen de Normalisation) Committee TC 283: Precious Metals Applications in Jewellery and Associated Products, are working on the preparation of international standards for jewellery, while the analytical techniques that could be standardized for the determination of fineness are being reviewed by the corresponding Working Group WG1.

\section{Spectrometric Methods}

Because of its high performance in the assay of standard gold jewellery materials, the specification in ISO/TC 174 N87 [2] for the cupellation method has met with international approval as referee method for the determination of gold. On the other hand, new develop- ments in the field of ICP (inductively coupled plasma) solution spectrometry indicate that this method could well become a viable alternative to cupellation. The high precision of the ICP method makes it equally suitable for the determination of precious metal contents of gold (N71), platinum (N67) and palladium (N69) in the corresponding jewellery alloys.

The use of spectrometric methods to analyse for the elements present, and hence determine the fineness of precious metal alloys in weight percent, can be considered only if the method could be relied upon to give results with variation coefficients of well under $1 \%$. In the particular case of coloured and white gold jewellery alloys, it is clear from the ISO-TC 174 working document $\mathrm{N} 50$ [3] that, for the analytical determination of the gold in gold-based alloys, greater precision is specified than for the main components of common base metal alloys. At the same time, this document also raises the question of the reliability of the determination of gold in the parts per thousand range of accuracy.

In a draft document, ISO/TC 174 WG1 N 71 [4], the ICP method for the determination of gold in gold jewellery alloys was considered as being the sole spectrometric method capable of serving as an alternative to cupellation. The required precision with a reproducibility of about one part per thousand (1\%o) gold can be achieved by the ICP method provided the following conditions are met:

1. Simultaneous measurement of the gold I line, $267.6 \mathrm{~nm}$, and the yttrium II line, $371.0 \mathrm{~nm}$, using yttrium as the internal reference element.

2. Buffering the strong hydrochloric acid-based aqueous solution of the gold in the presence of copper chloride and sodium nitrate.

3. Use of precision weighing to ensure exact aliquots of the solution of the gold jewellery sample and the added amount of the yttrium reference solution.

4. Measurement of the sample and calibration solutions with both prepared at the same time.

By taking these precautions, it has been possible to establish that cupellation is not more than five times better than ICP spectrometry.

The ICP method, as described in this paper, has the following important advantages with respect to cupellation:

- It permits the simultaneous determination of silver and palladium as well as gold. 
- Gold can be determined in materials for which cupellation cannot be used directly.

- It is well suited for automated analyses.

Undoubtedly, the confirmation of the suitability of the aqueous solution medium for the ICP determination of platinum, rhodium and iridium, as described below, is also of great interest. It is only with extreme difficulty that these precious metals can be determined by gravimetric techniques.

\section{ICP Spectrometry}

There can be little doubt that for a comparison of methods for the determination of gold in gold jewellery alloys for the purpose of fineness analysis no techniques could be more appropriate than cupellation and ICP spectrometry (Figure 1).

Whatever the purpose of the analysis of gold analytical quality control, hallmarking, recycling - in the comparison of available methods for gold jewellery alloys, cupellation with lead provides an accurate and reproducible gold value that is little short of 'disquiet- ing'. The high analytical performance of this method is unequalled, arising from the noble character of gold itself and the consequent marked tendency of the element to prefer the metallic state. It is therefore not surprising that cupellation is the obvious choice as criterion for comparison with a spectrometric substitute method. In other words, this means that in the case of gold it is somewhat venturesome to invite comparison with other methods.

The reasons for considering other methods are elucidated elsewhere [5]; as the underlying theme in the following account the question in the foreground is under which conditions the performance of ICP spectrometry, which in principle is known, as regards the development of a comparable determination of gold and also all the other precious metals - can be realized.

Here, it is evident that with the measuring signal of the gold ICP emission internally standardized by means of a foreign element such as yttrium, a reproducibility of between $0.01 \%$ and $0.1 \%$ is effectively attainable. It is encouraging to consider that for the rival technique of cupellation of white gold, the draft
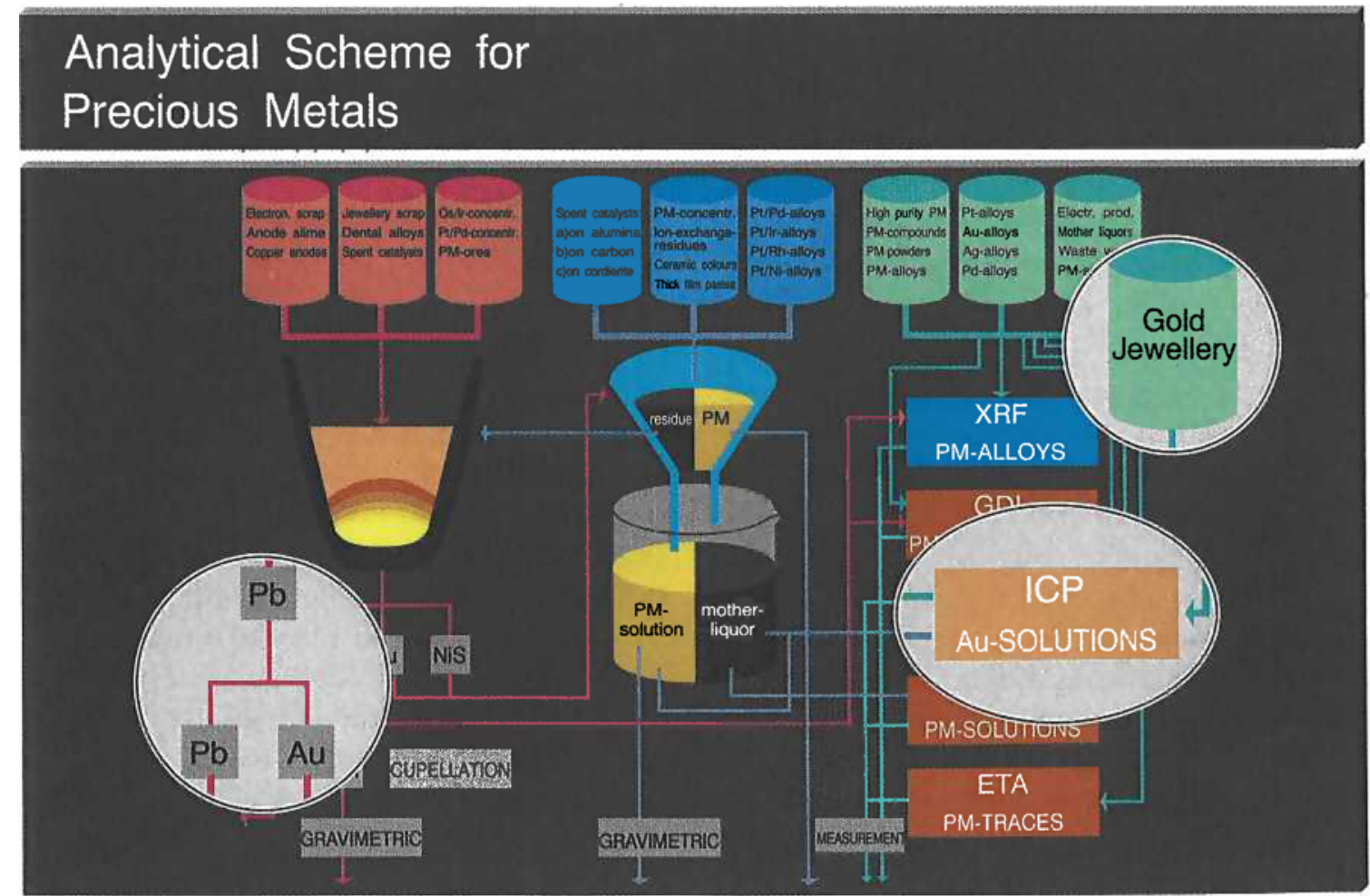

Figure 1 

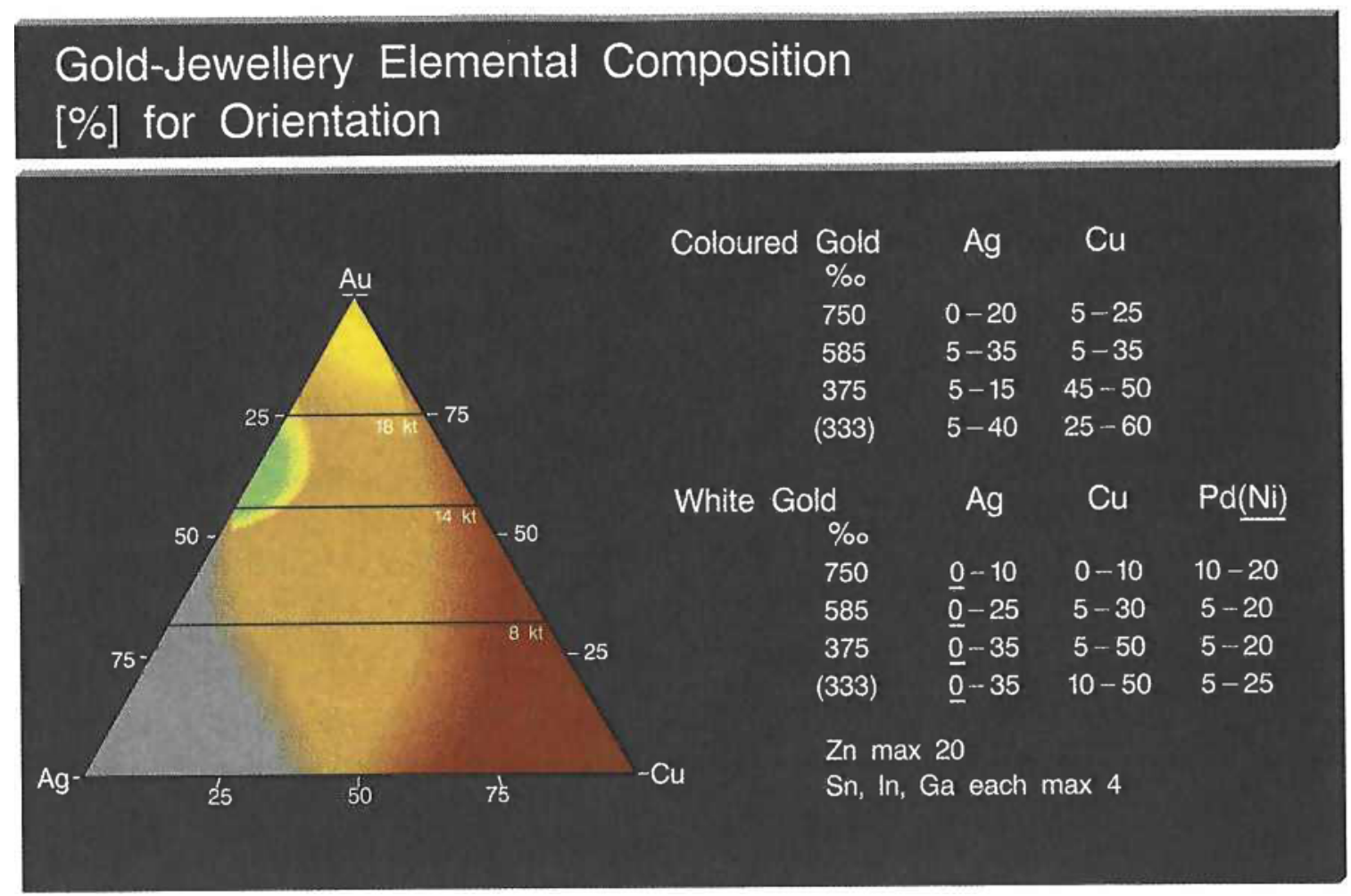

Figure 2

ISO standard on the réproducibility of cupellation specifies 'only' one part per thousand of gold [3].

Inevitably, the idea arises in this case of using the dissolved jewellery sample to determine silver and possibly also palladium at the same time. As a working hypothesis in the development of the solvent medium, the extent to which it is also suitable for the measurement of palladium, platinum, thodium and iridium should always be borne in mind. These elements exhibit roughly the same sensitivity in their ICP emissions as gold. Precious metal chemists will also appreciate this from the viewpoint that alternative gravimetric methods for rhodium and iridium cannot reasonably be considered as practicable. Incidentally, it may be mentioned here that preliminary draft ISO standards have been prepared for the ICP determination of palladium [6] and platinum [7] in the corresponding jewellery alloys on the same basis.

\section{EXPERIMENTAL}

\section{The Sample Material \& the Requirements for the Analysis of Gold}

The supposition that it will be possible to determine representative gold values with small samples of gold jewellery alloys [8] is supported by the following experimental facts: the arrangement of the elements $\mathrm{Au}$, $\mathrm{Ag}, \mathrm{Cu}, \mathrm{Pd}$ and $\mathrm{Ni}$ in the periodic system is reflected in their chemical and physical properties in that in liquid mixtures at the concentration ratios of jewellery alloys they exhibit mutual solubility. Solidification from the melt is dominated by the main components $\mathrm{Au}, \mathrm{Ag}$ and $\mathrm{Cu}$, and by means of the continuous casting technique, for example, material segregation during solidification can to a large extent be prevented. The generally applied additional mechanical working of the ductile alloys is finally a further factor contributing to 
material homogeneity so that even extremely small sample weights allow accurate and representative determination of the gold content. The logical outcome of this is found in the normal practice of cupellation of gold, where, with samples as small as 0.125 to $0.250 \mathrm{~g}$, reproducibility of the determination of gold to better than $1 \%$ can be achieved. As well as the generalized material structure of the alloys the colours that may be obtained are also of interest for jewellery applications (Figure 2).

The preliminary draft standard for gravimetric analysis of gold [3] differentiates as regards the required reproducibility between coloured gold $(0.5 \%)$ and nickel-containing white gold (1\%) and this is readily achievable by means of cupellation. The reproducibility requirement of $1 \%$ for nickel-containing white gold provided an opportunity for the analysts eager to promote the ICP method to use it as a basis for the systematic use of the method. The fact that palladiumcontaining white gold alloys were covered by the resulting draft standard on the ICP method [4], gave rise to the additional objective of avoiding the obstacles encountered when determining gold by the cupellation method in the presence of nickel and palladium.

Table 1:

Chemicals Used

for the ICP Method of Gold

a) Hydrochloric acid $\mathrm{HCl}$ $\left(\rho=1.16 \mathrm{~g} / \mathrm{cm}^{3}\right)$

b) Nitric acid $\mathrm{HNO}_{3}$ $\left(\rho=1.40 \mathrm{~g} / \mathrm{cm}^{3}\right)$

c) Pure Gold The gold content shall be at least $99.99 \%$

d) Spectral buffer solution: $268.3 \mathrm{~g} \mathrm{CuCl}_{2} \cdot 2 \mathrm{H}_{2} \mathrm{O}$ and $37.0 \mathrm{~g} \mathrm{NaNO}_{3}$ are dissolved in $400 \mathrm{ml}$ water and made up to $1000 \mathrm{ml}$ with water

e) Internal Standard Solution: $3.4121 \mathrm{~g} \mathrm{YCl}_{3} \cdot 6 \mathrm{H}_{2} \mathrm{O}$ are dissolved in $200 \mathrm{ml}$ water and after having added $100 \mathrm{ml}$ hydrochloric acid made made up to $1000 \mathrm{ml}$ with water.

\section{Procedure for the Determination of Gold in Gold Jewellery Alloys Using ICP (Inductively Coupled Plasma) Spectrometry}

Since the cupellation and ICP spectrometry methods for the analysis of gold in gold jewellery alloys are described in the ISO preliminary draft standards, references [3] and [4], experimental details can be omitted here. This account may also be taken as a commentary on the ISO drafts.

The simplicity of the ICP method for the determination of gold is illustrated by the following:

- the chemicals required (Table 1),

- the preparation of calibration and sample solutions (Table 2),

- the ICP emission lines to be measured for gold and yttrium (Au I: $267.6 \mathrm{~nm}$; Y II: $371.03 \mathrm{~nm}$ ),

- the model used for the numerical evaluation (Table 3).

It can be seen at once that the decisive criterion for the accuracy of the ICP technique corresponds to the reproducible determination of the quotient of the line

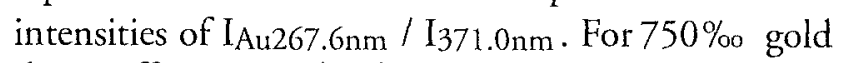
this coefficient can be determined at a probability of $95 \%$ with a variation coefficient or RSD (Relative

\section{Table 2:}

Measuring Solutions

for ICP Spectrometry of Gold

a) Calibration solutions:

Weigh out approx $30,45,60$, and $90 \mathrm{mg}$ pure gold $(99.99 \%)$ accuratley to $0.001 \mathrm{mg}$ and dissolve each in $800 \mathrm{mg}$ glass beakers with $150 \mathrm{ml}$ hydrochloric acid and $20 \mathrm{ml}$ nictric acid under heating. Add $100 \mathrm{ml}$ buffer solution and $350 \mathrm{ml}$ hydrochloric acid to the solutions. Let the solutions stand at approx $50^{\circ} \mathrm{C}$ for one hour. After cooling down transfer the solutions to $1000 \mathrm{ml}$ volumetric flasks. To each flask add $20.000 \mathrm{~g}$ of the internal standard solution weighed accurately to $0.001 \mathrm{~g}$. Afterwards make up the volume to $1000 \mathrm{ml}$ with water.

b) Sample solutions:

Weigh approximately $100 \mathrm{mg}$ of sample accurately to $0.001 \mathrm{mg}$, dissolve, and further treat as described under a) Calibration solutions. 
Table 3:

The Numerical Evaluation of Gold

by ICP Spectrometry

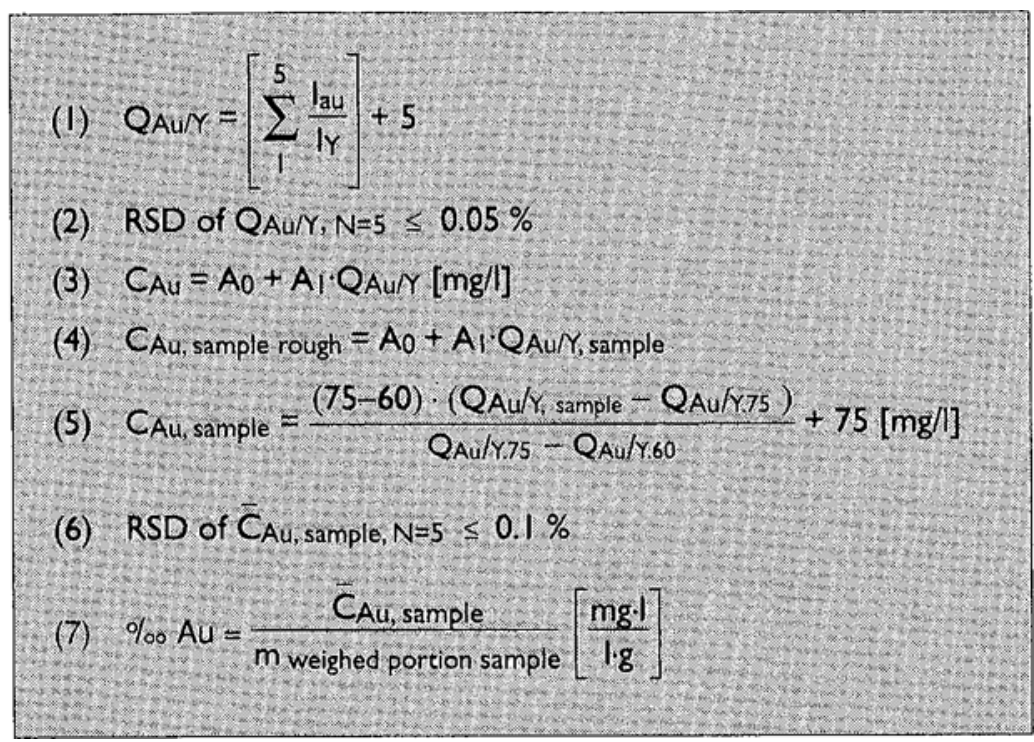

Standard Deviation) of $\leq 0.1 \%$ under simultaneous measurement of the two lines with an integration time of $5 \mathrm{~s}$ for each with the emission spectrometer. As is well known, to obtain optimum accuracy with the ICP method the absence of additive interference of possible accompanying elements on the gold and yttrium lines is a decisive prerequisite.

Table 4 is a synopsis of the research on possible interfering elements. It shows that the selected pair of Au and $Y$ lines in conjunction with the usual composition of gold jewellery alloys but also in the presence of numerous elements - for example in the case of gold dental alfoys [9] - can allow the determination of gold without interference. These facts and not least the composition of the solute medium used in the ICP excitation constitute the core of the analysis method.

The individual components of the ICP measuring solution, their concentrations and their probable effects are described below (Table 5).

\section{$\mathrm{Au}^{3+} 30$ to $100 \mathrm{mg} / 1$}

This corresponds to the range of the gold concentrations to be measured. The ICP signal for gold is to a large extent linearly dependent on the gold concentration in this range.

\section{$\mathrm{Y}^{3+} 20 \mathrm{mg} / \mathrm{l}$}

This concentration of the internal reference element yttrium equally as about $70 \mathrm{mg} / \mathrm{l}$ gold give rise to a signal-to-background ratio of about 100:1. To ensure the utmost accuracy, it is important to make sure that the precisely weighed quantity of $20.000 \mathrm{~g}$ yttrium standard solution is added to the calibration and sample solutions. Precision weighing is also used for possible division of a sample solution into aliquot parts. Thus, dilution of the solutions to the end volume of the measuring solution does not affect the accuracy. This procedure ensures that the requirement of high accuracy can be taken care of by simple means. Excessive care for what in practice will generally be a volume measurement in great demand is thus quite unnecessary.

\section{$\mathrm{Cu}^{++}(\mathrm{Cl})^{-1} 10000 \mathrm{mg} / \mathrm{l}$}

The relatively high copper concentration in itself already justifies the idea of a buffer solution. In the strongly acid solution medium, the high concentration 
Table 4:

Determination of Gold by ICP Spectrometry

Interfering Elements (10\% in Sample)

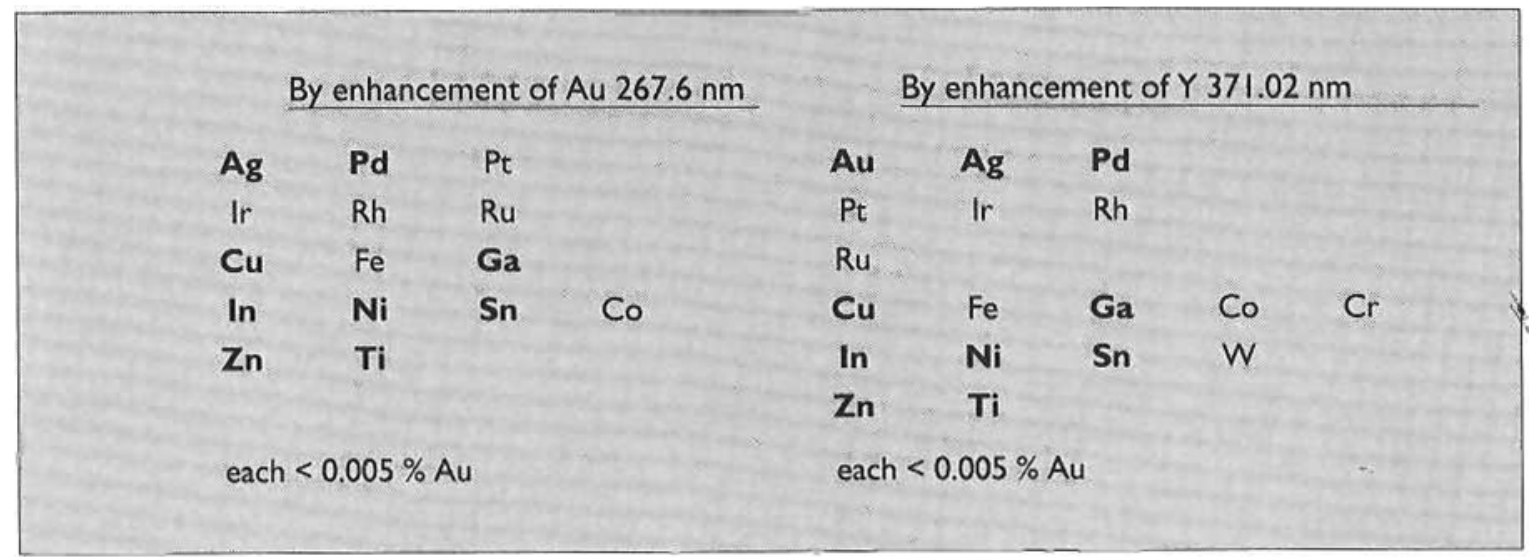

of copper ions additionally produce the oxidation potential necessary for the stabilization of $\mathrm{Au}^{3+}$. With the high proportion of copper there is, moreover, the possibility for a so-called quartation if metal samples do not immediately go into solution with acids. In this case, the sample $(100 \mathrm{mg})$ is melted with $5 \mathrm{~g}$ of copper. The resulting alloy of high copper content is then easily dissolved in the $\mathrm{HCl} / \mathrm{HNO}_{3}$ mixture. For adjustment of the copper concentration, copper chloride is added to bring the copper content of the measuring solution up to $10000 \mathrm{mg} / \mathrm{l}$. In the case of gold jewellery alloys, such a quartation is generally not necessary. The metal chips dissolve in the $\mathrm{HCl} / \mathrm{HNO}_{3}$ acid mixture when the following procedure is followed: after attacking with a little $\mathrm{HNO}_{3}$, the $\mathrm{HCl}$ part is added; as the remaining $\mathrm{HNO}_{3}$ is then added bit by bit the sample

Table 5:

Components of the Measuring Solution to Determine Gold by ICP

\begin{tabular}{|lrl|}
\hline $\mathrm{Au}^{+++}$ & 30 to $100 \mathrm{mg} / \mathrm{l}$ & $\begin{array}{l}\text { dynamic range } \\
\text { linear }\end{array}$ \\
$\mathrm{Y}^{+++}$ & $20 \mathrm{mg} / \mathrm{l}$ & $\begin{array}{l}\text { internal standard } \\
\mathrm{Cu}^{++}\left(\mathrm{Cl}^{+}\right)\end{array}$ \\
$\mathrm{HCl}(32 \%)$ & $5000 \mathrm{mg} / \mathrm{vol} \%$ & $\begin{array}{l}\text { chemical buffer } \\
\text { complexing agent } \\
\mathrm{AgCl}_{2}^{-}\end{array}$ \\
$\mathrm{Na}^{+}\left(\mathrm{NO}_{3}\right)$ & $1000 \mathrm{mg} / 1$ & ionisation buffer \\
\hline
\end{tabular}

dissolves on heating. (The quartation type procedure is mainly of importance for certain platinum and palladium based materials that sometimes do not readily dissolve in aqua regia.)

\section{$\mathrm{HCl}(32 \%) 50$ vol.\%}

The final measuring solution is thus effectively $16 \%$ hydrochloric acid. This makes it possible for some $50 \mathrm{mg} / \mathrm{l}$ of silver to be held in solution with preferential formation of the $\mathrm{AgCl}_{2}$ complex. In this respect, the solutions have long term stability so that the silver can be determined by the ICP method at the same time as gold in the jewellery alloy solution.

\section{$\mathrm{Na}^{+}\left(\mathrm{NO}_{3}^{-}\right) 1000 \mathrm{mg} / \mathrm{l}$}

The sodium fraction allows for unforeseeable alkali concentrations in the solution of the precious metal samples. However, in any event, the relatively high alkali concentration has a stabilizing effect on the temperature and electron density of the ICP plasma.

Despite the fact that this solution medium appears to be strategically optimum for gold and silver, solutions made in this way are not sufficiently stable in view of the extremely high requirements for the measuring accuracy of the gold intensity. As is not unusual for transition metals it seems probable that the root cause of this is a progressive complex-ligand exchange at the $\mathrm{Au}^{+++}$central atom ion. To compensate for this effect, it has been established that the calibration and sample solutions should be prepared at the same time if the 
Table 6:

Repeatability in Determining Gold [0/oo]

by ICP and Cupellation

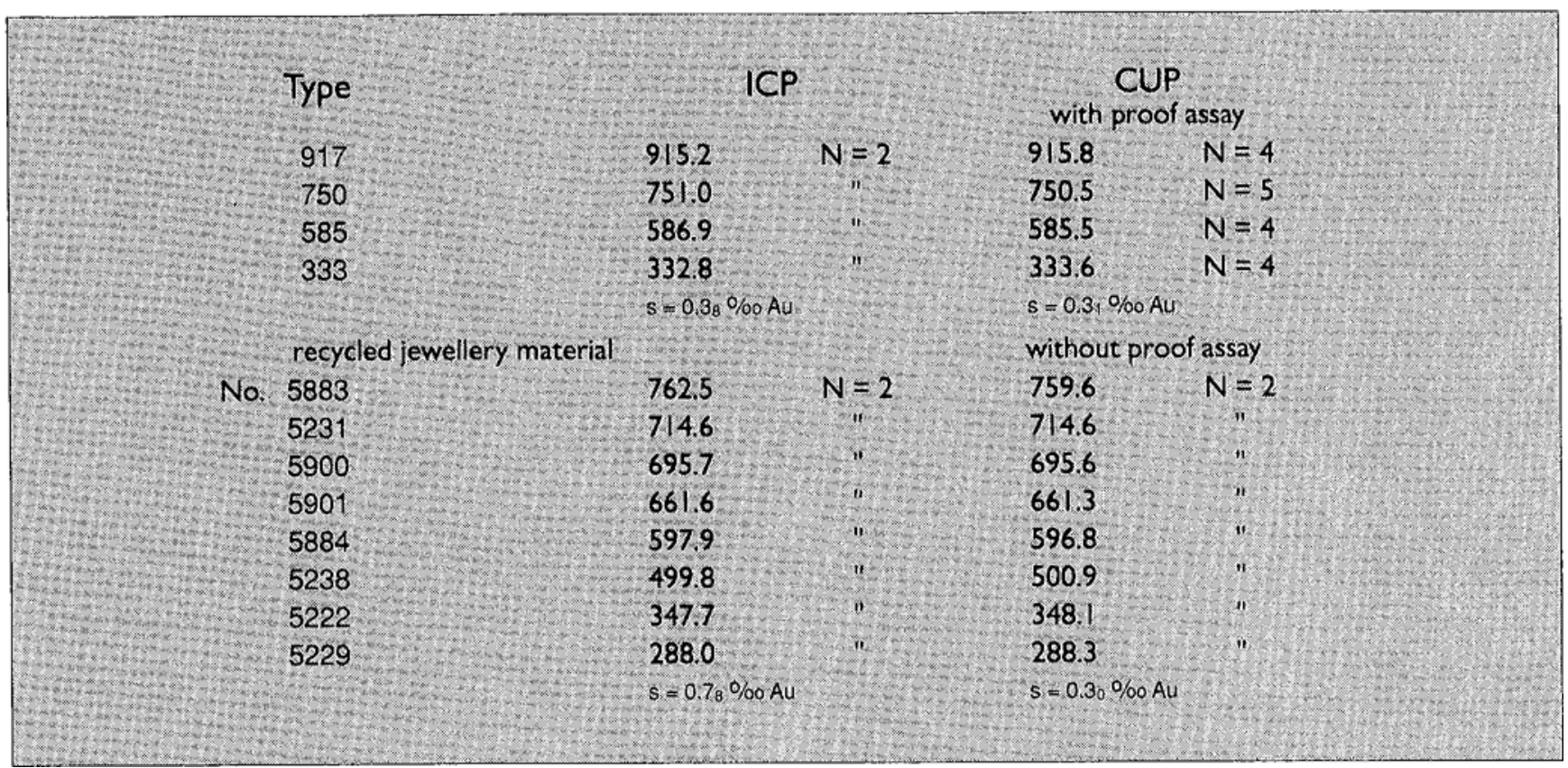

utmost accuracy of the method is to be obtained. As regards the precious metals palladium, platinum, rhodium and iridium, this effect does not show itself so clearly. It has proved best to subject the calibration and sample solutions to the shortest possible measuring cycles and to replace the calibration solution by a freshly prepared solution after one week.

Table 7:

Cupellation Results of Gold in White Gold Containing Nickel after Scorification

\begin{tabular}{|ccc|}
\hline & Au $\%$ & \\
\hline Type & FoundN=12 & SN=12 \\
$335+1$ & 336.11 & 0.20 \\
$590+1$ & 590.72 & 0.14 \\
$750+1$ & 750.77 & 0.23 \\
Synthetic - without proof assay \\
750 to & 749.77 & 0.23 \\
\hline
\end{tabular}

The ICP Results for Gold

\& Evaluation in Comparison with Cupellation

The possibility of choosing cupellation as the comparison method for the evaluation of the ICP analysis is particularly fortunate. For gold jewellery alloys, cupellation is to be regarded as an absolute method. Although there can be no doubt about this, an available set of gold determinations in nickel-containing white gold yields the listing given in Table 7 . In addition, values are shown for synthetic material which confirm the accuracy of the gold value obtainable by cupellation $[10,11]$.

The high quality of the cupellation method thus makes it ideal for comparison with the ICP spectrometry of gold. Table 6 shows corresponding comparative determinations carried out on characteristic coloured gold jewellery alloys [12]. At the same time, a few gold results from routine analysis of recovered jewellery material are reproduced. On the basis of the corresponding standard deviation indicated it is seen that 


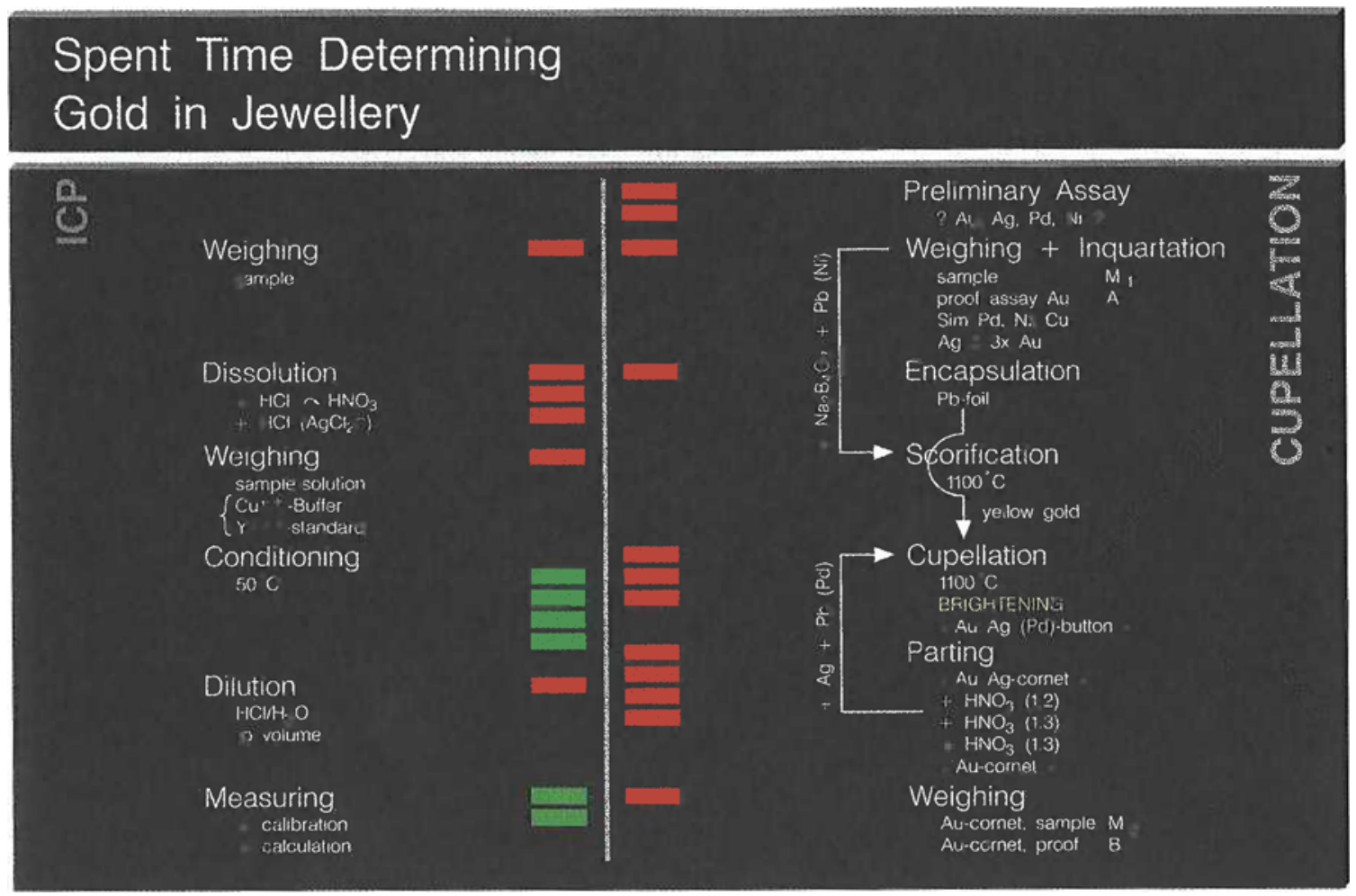

Figure 3

roughly speaking cupellation cannot be more than 5 times better than ICP. Considered outside the context of the wide range of conditions in which analysis of gold has to be applied, this statement could easily be seen as disadvantageous to IC. Moreover, it is supported by the fact that the cupellation of gold - particularly in the case of $\mathrm{Au} / \mathrm{Ag} / \mathrm{Cu}$ jewellery - can be carried out in as little as 120 minutes. The attempt to extend this analysis to alloys of more complex composition multiplies the effort considerably for cupellation - palladium is a good example of this. Also, one has only to consider that in the field of analysis of goldcontaining dental alloys [9] the fact that the repeatability attainable immediately with ICP of about $1 \%$ gold represents an excellent result for the determination of gold. For comparison of the time required for the two methods the individual operations are represented in simplified form in Figure 3.

A little background should further elucidate the performance of ICP spectrometry.

Because of the extensive dynamic range and reproducibility on the one hand and the powerful detection of the precious metals on the other, ICP emission is breaking into the domain of 'fineness analysis' to a significant extent. The truth of this statement for various precious metals is still being examined for the model case of gold which from the chemical aspect is by no means the least favourable.

In Figure 4, the variation coefficients for each of five consecutive measurements of the $\mathrm{Au} / \mathrm{Y}$ intensity ratio are plotted against the corresponding relative cumulative frequency. The gain in reproducibility as the gold and yttrium concentrations are increased can be clearly seen. By giving up the high linearity a further reserve in the dynamic range is available to increase still further the quality of the measurement. Also noteworthy is the fact that by modification of the stabilizing circuit of the high frequency generator using the latest technology it is possible to considerably improve the reproducibility of the measuring process. It should be recalled at this point that the exceptionally promising reproducibility although it certainly provides a necessary quality of ICP gold determination is however by no means a sufficient condition. For checking the 


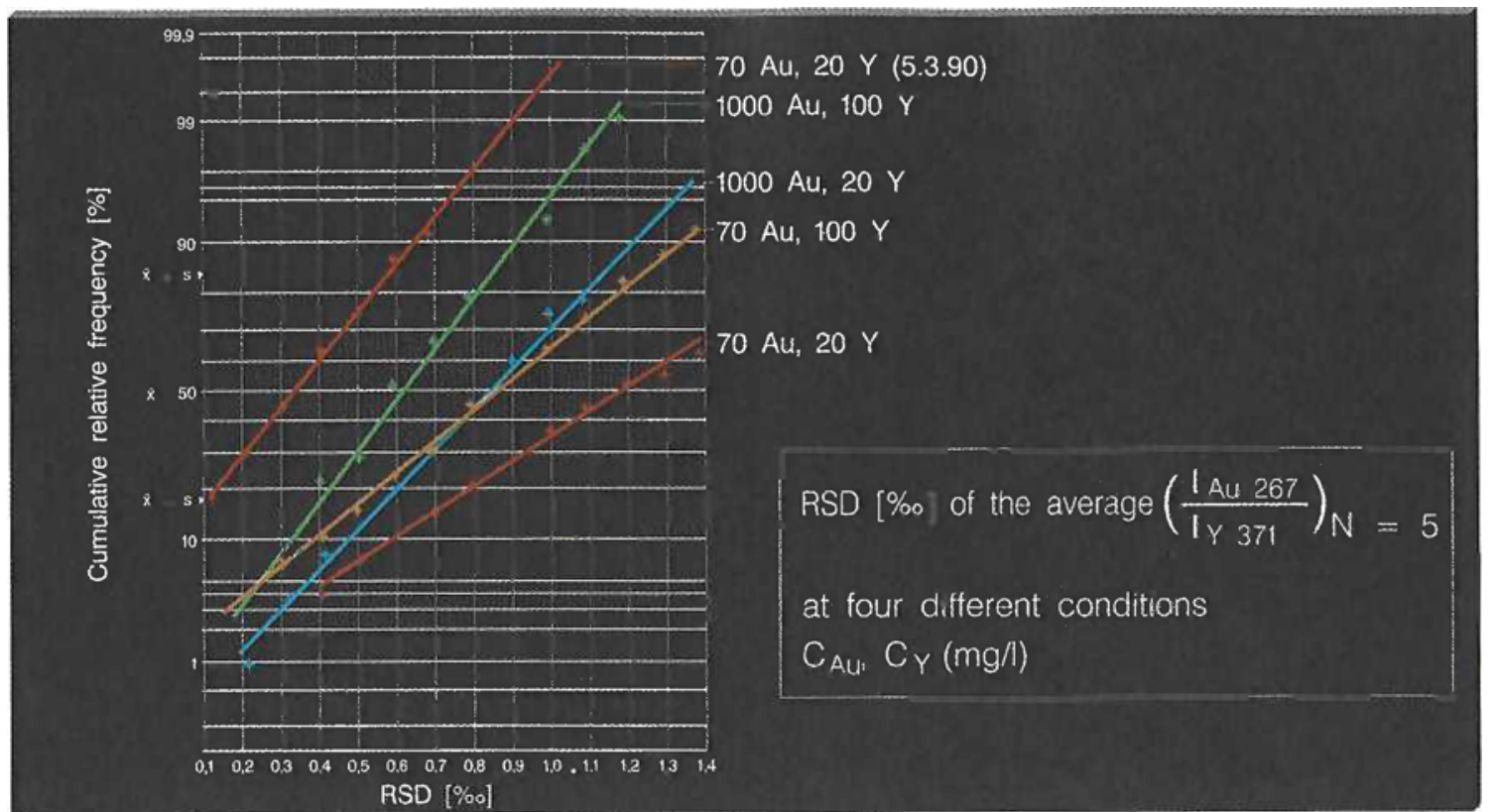

Figure 4:

Reproducibility Analysis for the ICP Determination of Gold

accuracy, multiple determinations and parallel measurements on known test specimens must not be dispensed with.

\section{Table 8:}

Determination of Gold and Silver in Jewellery with ICP of $5 \mathrm{mg}$ Samples

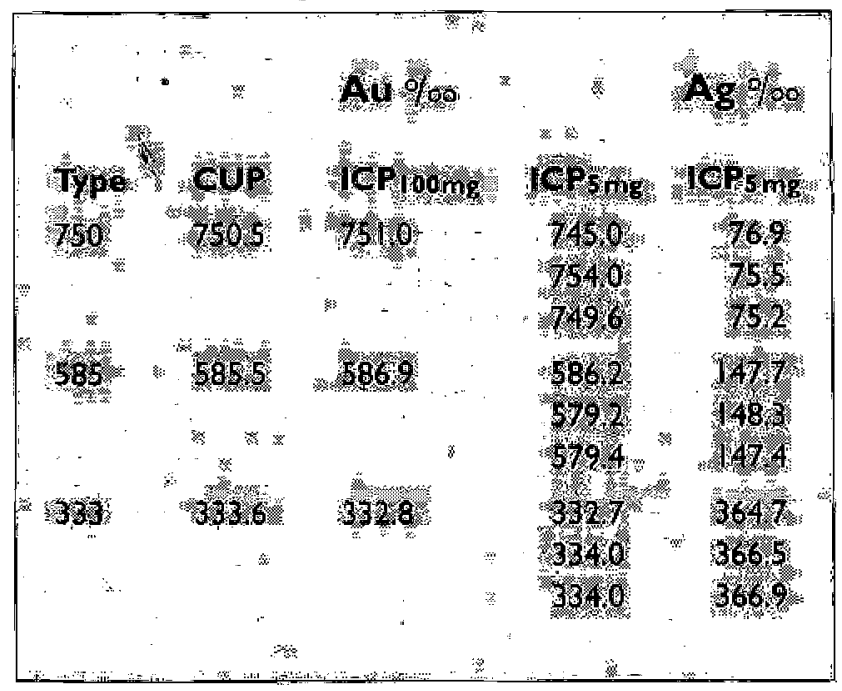

The performance of the ICP method as regards sensitivity is shown in Table 8. On the basis of accurately weighed $5 \mathrm{mg}$ samples of the most current jewellery alloys with 750, 585 and $333 \%$ gold in each case the gold and silver content was simultaneously determined by the ICP method. Nevertheless, using the original method $50 \mathrm{ml}$ of the measuring solution were still available. Even with $5 \mathrm{ml}$ of measuring solution or $0.5 \mathrm{mg}$ of the jewellery sample it is possible that a meaningful analysis for gold and silver may be carried out under these conditions; this gives rise to the concept of an 'ICP precision touchstone'.

\section{Equipment}

Evidently, the spectrometer configuration used is of major interest $[13,14]$. It is shown in the simplified block diagram of Figure 5 . The diagram also indicates the particular measuring lines and other relevant lines. The spectrometer can thus be described as a simultaneous-sequential emission spectrometer [15]. For appraisal of the choice of optical parameters of the indi- 
Table 9:

The Technical Specifications

of the Simultaneous ICP Spectrometer

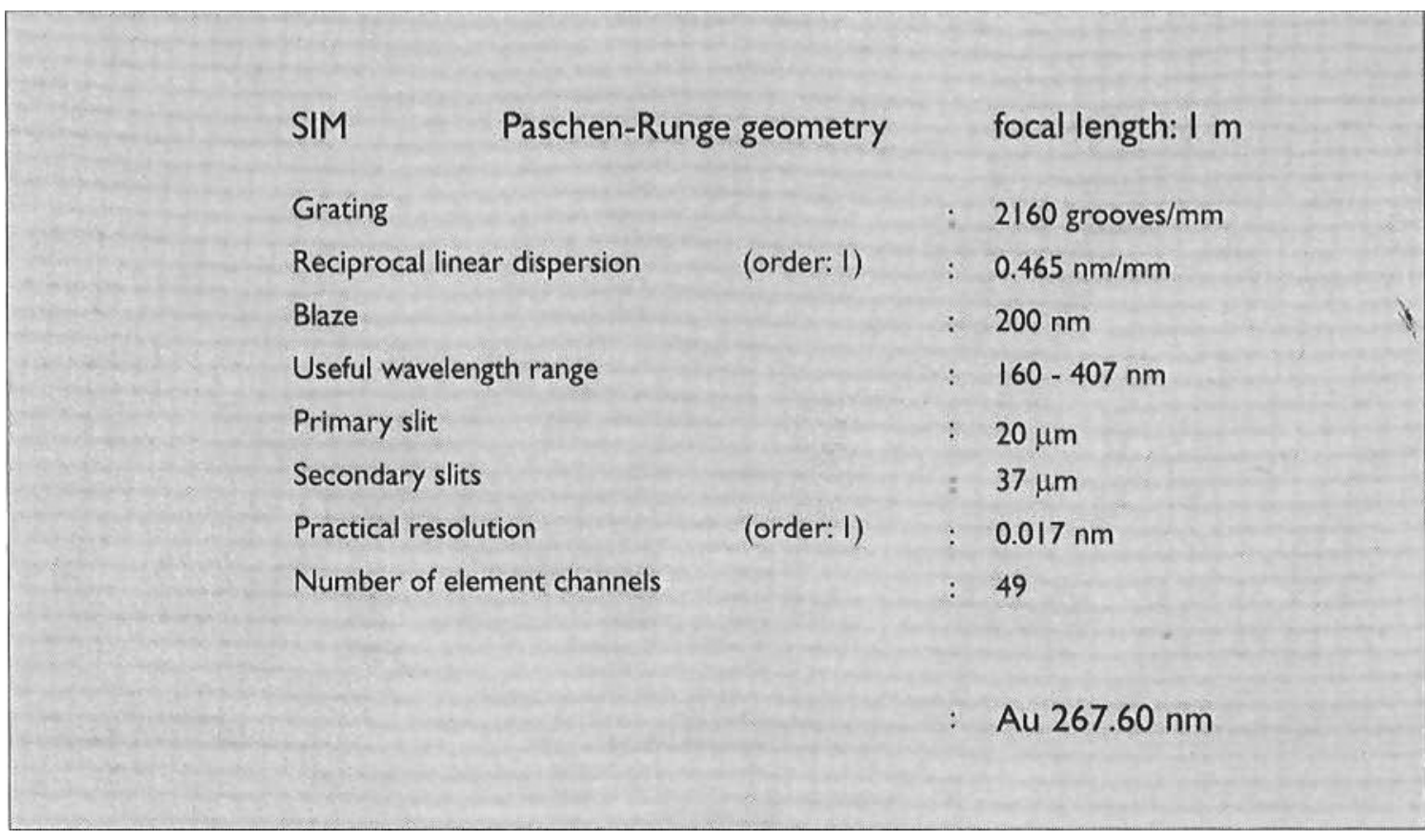

Schematic Principle of the Spectrometric Configuration

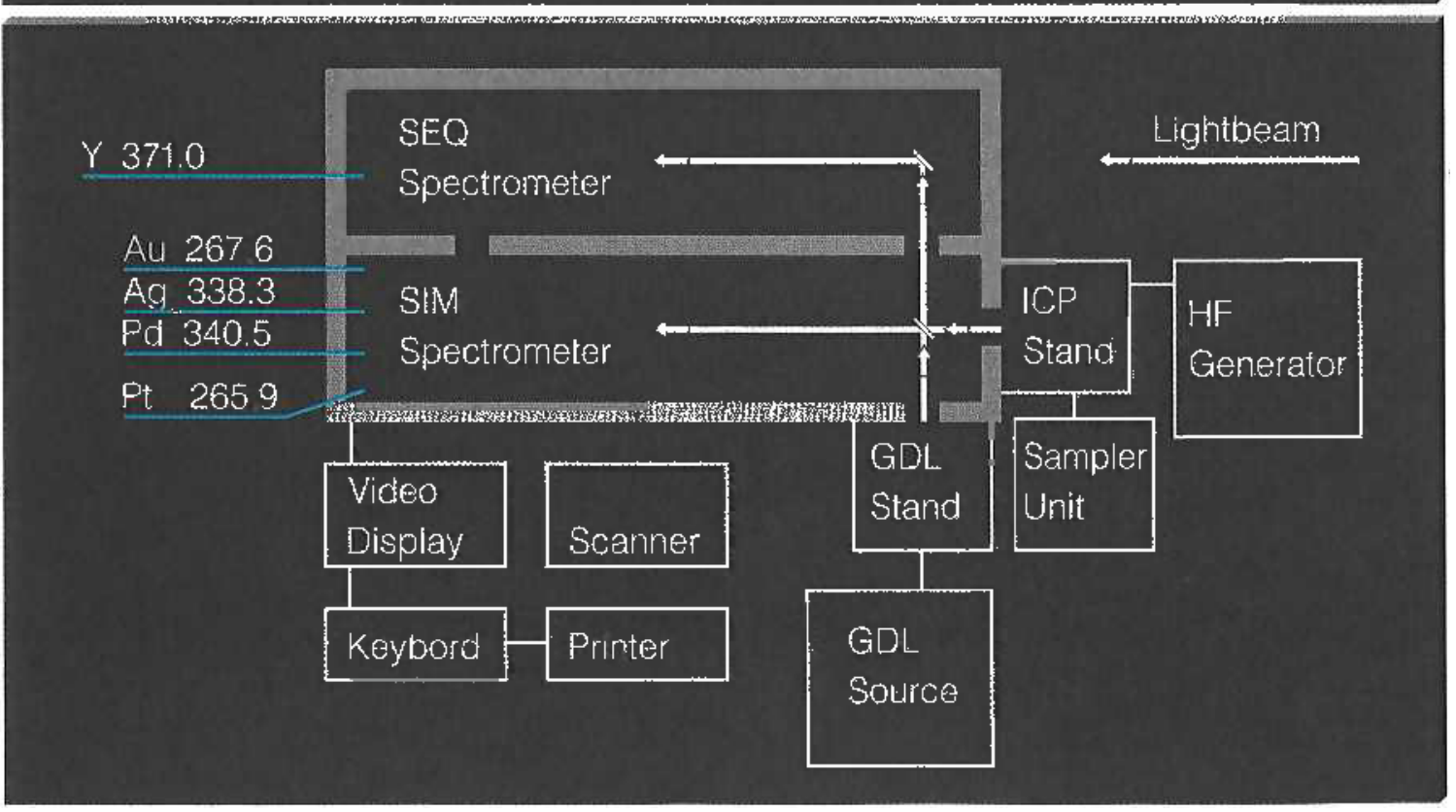

Figure 5 


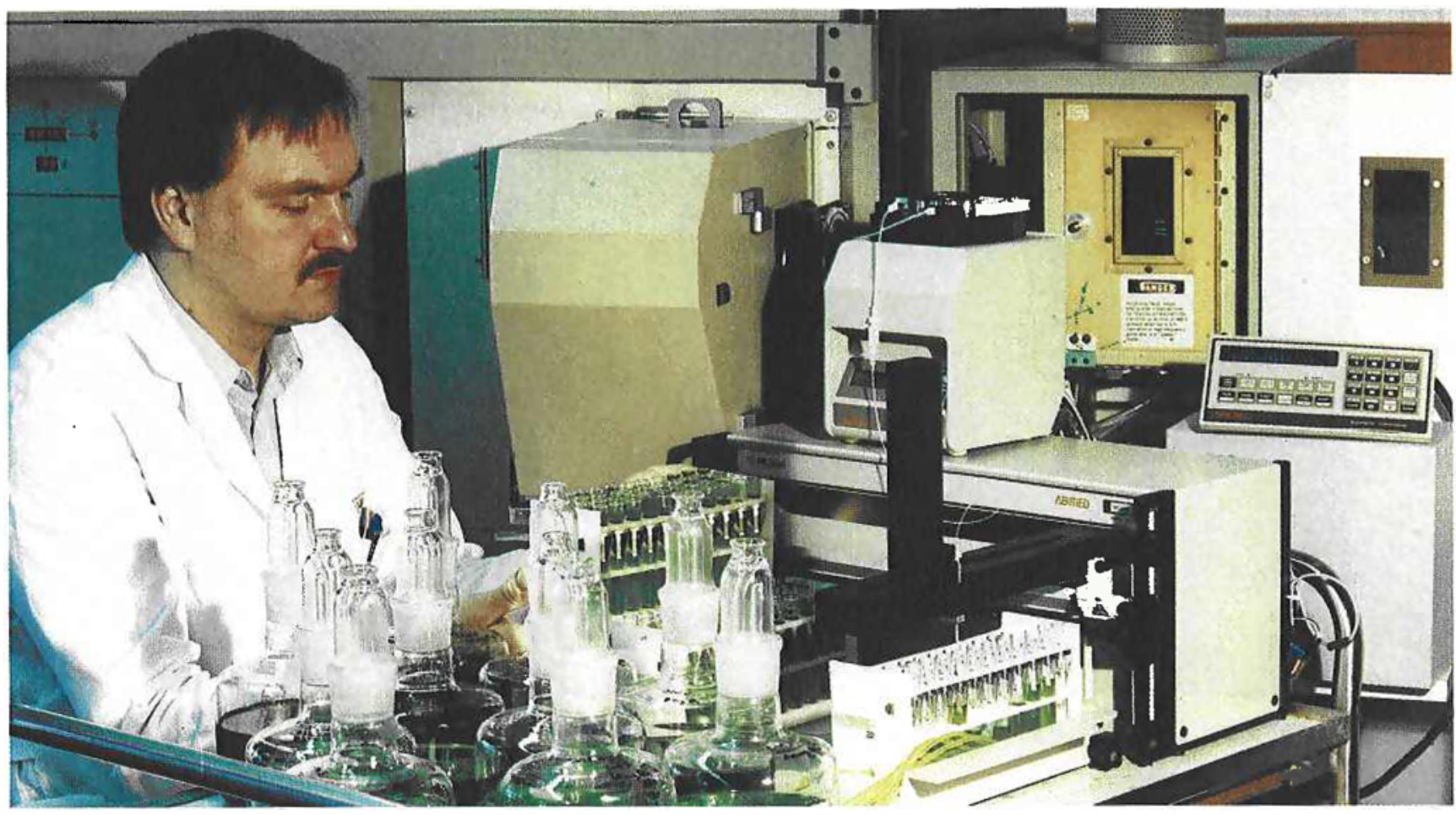

Figure 6:

One of the Authors (K.-H. Wiedemann) Calibrating the ICP Spectrometer

Table 10:

The Technical Specifications of the Sequential ICP Spectrometer

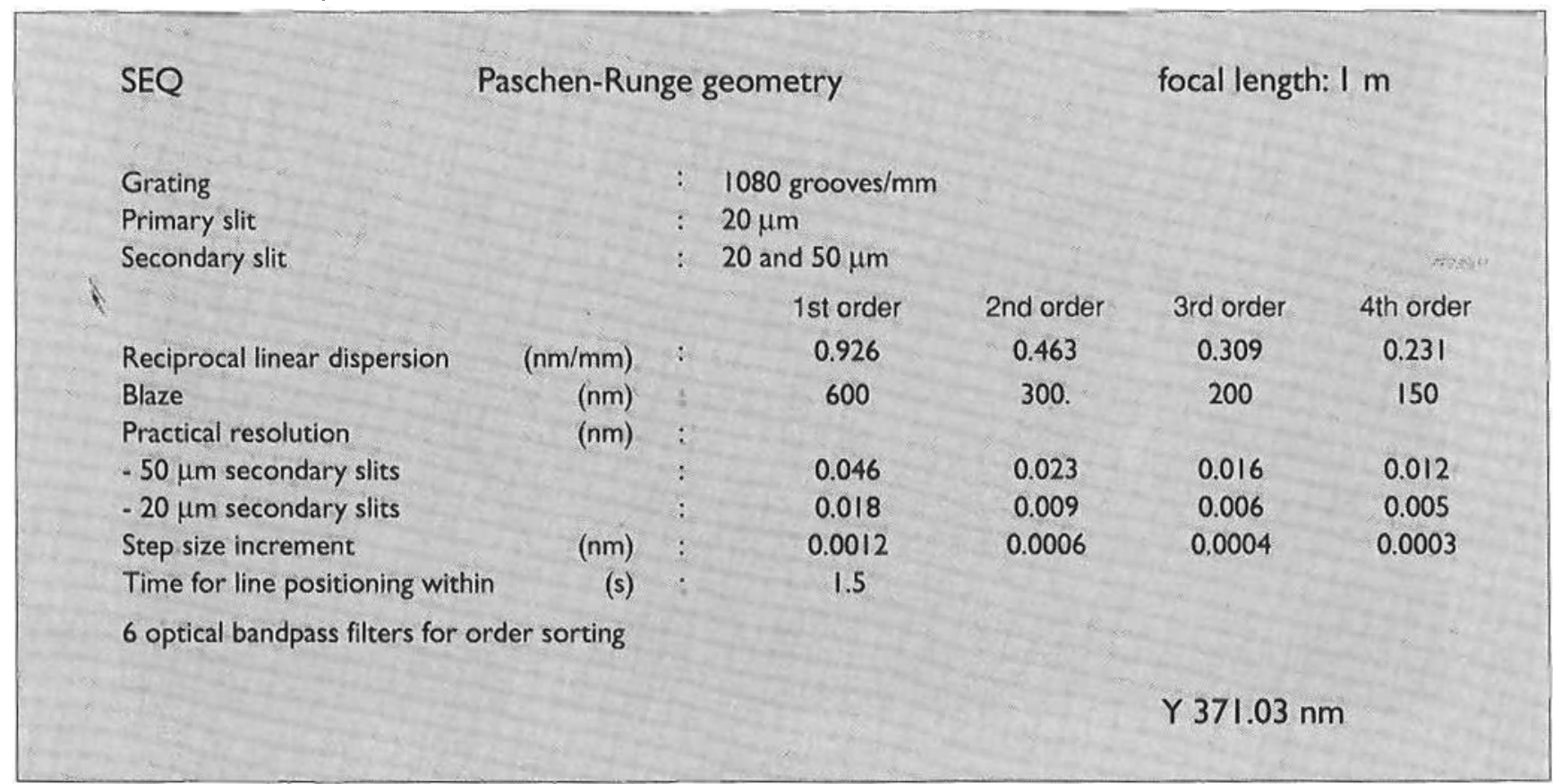


Table 11:

Physical Parameters of the ICP Light Source

Henry radio frequency generator as

- Inductively Coupled argon Plasma source -

Excitation unit operating at

$27.12 \mathrm{MHz}$

Maximal power output $2500 \mathrm{~W}$

Operating conditions:

Forward power

Atomizer Ar gas flow

Sample uptake

Auxiliary Ar gas flow

Coolant Ar gas flow

Viewing height

$1200 \mathrm{~W}$

$1 \mathrm{l} / \mathrm{min}$

$2 \mathrm{ml} / \mathrm{min}$

$0.8 \mathrm{l} / \mathrm{min}$

$12 \mathrm{l} / \mathrm{min}$

$15 \mathrm{~mm}$

cated measuring lines of gold and yttrium the corresponding data for the simultaneous spectrometer are emphasized in Table 9 and those for the monochromator part in Table 10.

It has proved extremely useful to supply the measuring solutions to the ICP torch by means of a sampling apparatus. In this way it is possible, for example, without great difficulty, to measure the sample solution so that it is bracketed by successive calibration solutions, thereby appreciably increasing the accuracy of the value obtained. The vessels containing the supplies of calibration solutions are connected by tubing communicating with the appropriate sample tubes. The physical arrangement is shown in Figure 6. Regarding the use of this multifunction spectrometer arrangement, automatic ICP spectrometry represents the optimum in unattended laboratory time.

Finally, the physical data of the actual plasma sources are reproduced in Table 11.

\section{Conclusions \& Prospects}

Comparison of the performance of the two analysis methods for gold - cupellation and ICP spectrometry - can serve to weigh the arguments for the use of one or other method in the field of jewellery alloys. This comparison is summarized in critical form in Table 12. Notwithstanding the outstanding quality of the cupellation method it should not be overlooked that for

various reasons its position as the universal method for gold is controversial. It would be unwise in this connection to lose sight of the outstanding performance of cupellation of gold [16]. It should be remembered that the docimastic collection of precious metals - in particular, gold [17] - is of general importance in the context of the analysis of complex recovered material. It will be clear that this account aims to show that ICP spectrometry is also outstandingly well suited for the analysis of gold and that it represents a valuable complementary component of the analytical strategy of precious metal chemistry.

Why the performance range of ICP spectrometry is only gradually being appreciated is certainly to be ascribed to the apparently greater specificity of the ICP methods. Apart from the mostly quickly checked ad-

Table 12:

Comparison of the Performance of the two Methods

\begin{tabular}{|c|c|c|}
\hline Property & ICP & Cupellation \\
\hline Accuracy & + & + \\
\hline Reproducibility & $1 \% \mathrm{Au}$ & $0.2 \% \mathrm{Au}$ \\
\hline Speed for $\mathrm{Au} \mathrm{Ag} \mathrm{Cu}$ & + & + \\
\hline $\begin{array}{l}\text { Speed for } \mathrm{Au} \mathrm{Ag} \mathrm{Cu} \mathrm{Pd} \\
(\mathrm{Ni})\end{array}$ & + & - \\
\hline $\begin{array}{l}\text { Simultaneous estimation } \\
\text { of } \mathrm{Au} \mathrm{Ag} \mathrm{Pd}\end{array}$ & + & - \\
\hline $\begin{array}{l}\text { ditto for minimal sample } \\
\text { weight }(5 \mathrm{mg})\end{array}$ & + & - \\
\hline $\begin{array}{l}\text { Free of interference } \\
\text { from } \mathrm{Pt} R \mathrm{Rh} \text { Ir }\end{array}$ & + & - \\
\hline $\begin{array}{l}\text { Generalization for other } \\
\text { precious metals }\end{array}$ & + & - \\
\hline Automatic operation & + & - \\
\hline Environment & + & - \\
\hline Low-cost equipment & - & + \\
\hline
\end{tabular}


ditive interference effects, such as the line interference, the element signals appear to undergo multiplicative interference so that the radiation performance of the central atom ion is affected by the different effects of complex ligands. The kind of coupling of the high frequency power and possible 'atomization mechanics' of the solution do not, however, seem to be involved in this chemical-thermochemical effect. This and, for example, also the widespread misconception that for internal standardization only atom line pairs or ion line pairs lead to a successful result - Au 267.6 is an atom line and Y 371.0 an ion line [18] - makes one wonder whether the state of knowledge of ICP has already reached its achievable level. A further factor is therefore added to this unclear situation, namely, that on the basis of better knowledge of the solution chemistry, the measuring strategy and the undoubted further development possibilities of experimental techniques, ICP spectrometry will in the future be capable of analysing elements with virtually any desired degree of precision.

\section{References}

1 W. Wälchli and P. Vuilleumier, 'Assaying Gold by Cupellation', Aurum, 1987(No. 29), 56-64; Gold Technology, 1991(No. 3), 19-27.

2 International Organization for Standardization, Doc. ISO/TC 174 N87, June 1988

3 International Organization for Standardization, Doc. ISO/TC 174 N50, June 1988
4 International Organization for Standardization, Doc. ISO/TC 174 WG 1 N 71, Milano, Oct. 1989

5 M. Brill, 'Bericht über das Geschäftsjahr 1988', Fachvereinigung Edelmetalle e.V. Düsseldorf, pp. 6384 (1989)

6 International Organization for Standardization, Doc. ISO/TC 174 WG 1 N 69, Milano, Oct. 1989

7 International Organization for Standardization, Doc. ISO/TC 174 WG 1 N 67, Milano, Oct. 1989

8 Heraeus Edelmetalle GmbH, Edelmetall-BijouterieLegierungen, Hanau, 1986

9 Heraeus Edelmetalle GmbH, Edelmetall-Dentallegierungen, Technische Daten, Hanau, 1986

10 K. Aldinger, 'Personal Communication', Pforzheim, 1989

11 H. Knosp, 'Personal Communication', Pforzheim, 1989

12 H.-M. Lüschow, 'Personal Communication', Hanau, 1989

13 M. Brill, 'Proceedings International Precious Metals Conference (IPMI)', Brussels 1987, 369-400

14 M. Brill, 'PTB-Bericht des 78. Seminars', PhysikalischTechnische Bundesanstalt, Braunschweig, 1989, 187 206

15 Applied Research Laboratories SA. Manuel 3580/1186, Ecublens, 1984

16 The Gold Institute, Washington D.C., 'The Fire Assay of Gold', January 1985

17 E. E. Bugbee, 'Textbook of Fire Assaying', ed. J. Wiley \& Sons, Inc., New York, 1940

18 M. Brill, P. Cassagne, 'European Winter Conference on Plasma Spectrochemistry', Dortmund, January 1991 